
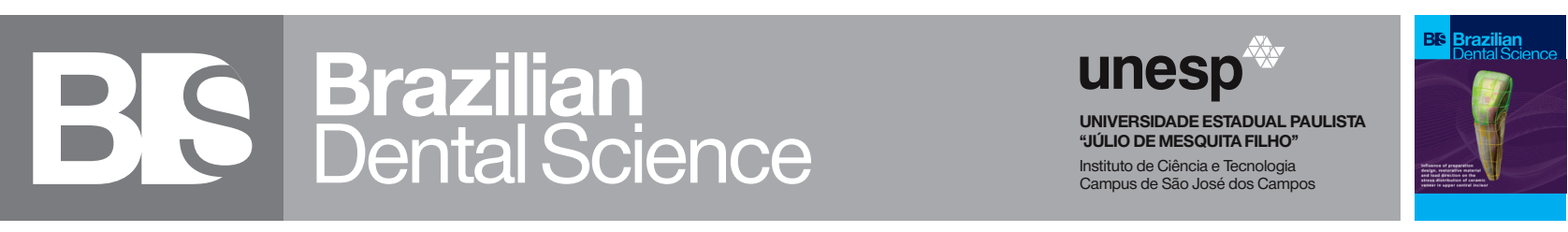

\title{
Evaluation of muscle involvement \& degeneration in advanced oral submucous fibrosis using three different stains - a retrospective cross-sectional study
}

Avaliação do envolvimento e degeneração muscular na fibrose submucosa oral avançada usando três colorações diferentes - um estudo transversal retrospectivo

Krishnapriya UMASHANKAR ${ }^{1}$, Herald SHERLIN ${ }^{1}$, Gifrina JAYARAJ ${ }^{1}$, Kanchi Ravi DON ${ }^{1}$, Archana SANTHANAM ${ }^{1}$

1 - Department of Oral Pathology, Saveetha dental college and hospital, Saveetha Institute of Medical and Technical Sciences, Chennai-600077, Tamil Nadu, India.

\begin{abstract}
Background: Oral submucous fibrosis (OSMF) is graded according to various histological factors which include the epithelial changes and the connective tissue changes. These features could be identified in routine Hematoxylin and Eosin ( $\mathrm{H}$ and E) staining in shades of pink. However, the use of special stains provides a contrast to various connective tissue components thereby aiding in better visualization of these connective tissue changes in advanced OSMF cases. Objective: To compare and evaluate muscle involvement and degeneration in advanced oral submucous fibrosis using three different stains namely, H\&E, Van Gieson, and Masson's Trichrome. Material and Methods: 10 Formalin-fixed paraffin-embedded tissue sections of advanced OSMFwere stained using 3 different stains namely Hematoxylin and Eosin (H\&E), Van-Gieson, and Masson trichrome. The results obtained were tabulated and statistically analyzed using Kruskal Wallis ANOVA. Results: The hyalinization and fibrosis involving the skeletal muscle were better visualized in Masson's Trichrome but were not statistically significant. The muscle degeneration in deeper areas was better visualized in Masson's trichrome when compared to the H\&E and Van Gieson. Conclusion: Hematoxylin and eosin stains all the connective tissue components in various shades of pink, use of special stains bestows contrast between different components of connective tissue, thus improvising grading of OSMF. Masson's trichrome stain can be used as a single adjunct to hematoxylin and eosin stain as changes in the superficial and deeper connective tissue could be ascertained.
\end{abstract}

\section{KEYWORDS}

Fibrosis; Masson's trichrome stain; Muscle degeneration; Oral submucous fibrosis grading.

\section{RESUMO}

Contexto: A fibrose submucosa oral (FSO) é classificada de acordo com vários fatores histológicos que incluem alterações epiteliais e do tecido conjuntivo. Essas características podem ser identificadas na coloração de rotina com Hematoxilina e Eosina (H\&E) em tons de rosa. No entanto, o uso de colorações especiais fornece um contraste para vários componentes do tecido conjuntivo, auxiliando assim na melhor visualização dessas alterações do tecido conjuntivo em casos avançados de FSO. Objetivo: Comparar e avaliar o envolvimento e degeneração muscular da fibrose submucosa oral avançada usando três colorações diferentes: H\&E, Van Gieson e Tricrômio de Masson. Material e Métodos: 10 seções de tecido fixadas em formalina e embebidas em parafina de FSO avançada foram coradas usando essas três colorações. Os resultados obtidos foram tabulados e analisados estatisticamente por meio do teste de Kruskal Wallis. Resultados: A hialinização e fibrose envolvendo o músculo esquelético foram melhor visualizadas no tricromo de Masson, mas não foram estatisticamente significativas. A degeneração muscular em áreas mais profundas foi melhor visualizada no tricrômico de Masson, quando comparado ao H\&E e Van Gieson. Conclusão: Hematoxilina e Eosina coloram todos os componentes do tecido conjuntivo em vários tons de rosa. O uso de colorações especiais confere contraste entre os diferentes componentes do tecido conjuntivo, melhorando assim a avaliação da FSO. A coloração com tricrômio de Masson pode ser usada como um único adjunto para a coloração de Hematoxilina e Eosina, pois assim é possível verificar alterações superficiais e profundas no tecido conjuntivo.

\section{PALAVRAS-CHAVE}

Fibrose; Coloração tricrômica de Masson; Degeneração muscular; Classificação da fibrose submucosa oral. 


\section{INTRODUCTION}

$\mathrm{O}$ ral Submucous Fibrosis (OSMF) was first described by Schwartz in 1952, as "Atrophia idiopathica mucosa oris," and was later coined the term as OSMF by Joshi in 1953 $[1,2]$. OSMF is a potentially malignant disease predominantly seen in the people of South-Asian countries [2]. The malignant potential rate of OSMF is $7.6 \%$ and is particularly associated with the use of areca nut in various forms with a significant duration and frequency of chewing habits [1,2]. The histopathological changes associated with OSMF have been studied by many authors previously [2]. The characteristic histopathological features usually described concerning OSMF are chronic inflammation leading to juxta epithelial hyalinization with excessive collagen deposition (fibrosis) in the connective tissue extending into the adjacent muscle with muscle degeneration and an atrophic epithelium [1-3].

The presence of a homogenous, collagenous sub-epithelial zone along with degeneration of muscle fibres and loss of cross striations, oedematous muscle fibres and atrophy are also observed as light microscopic changes in OSMF $[1,2]$. However, another distinctivefinding noticed while carefully examining histopathological sections of OSMF under light microscope is a progressive decrease in the distance of muscle fibres from the epithelial surface as the lesion advances brought about by the profound fibrosis extending into the underlying skeletal muscle [13]. Khanna and Andrade et al classified OSMF based on these histopathological changes in routine Hematoxylin and Eosin (H\&E) staining as very early OSMF, early OSMF, moderately advanced OSMF, advanced OSMF [4]. Various authors stated that restricted mouth opening in cases of OSMF not only depends on subepithelial fibrosis but also the extent of muscle damage and demonstrated various ultrastructural muscle changes in patients with restricted mouth opening [1-3]. The early and very early stages of OSMF are reversible conditions whereas the moderately advanced and advanced OSMF are irreversible conditions of the oral mucosa which causes sunken cheeks and progressive inability to open the mouth [4].

OSMF, though associated with a high malignant transformation rate, begins as a connective tissue pathology and hence a series of morphological alterations are visible in the lamina propria of the affected mucosa. Although these connective changes can be appreciated in the routine hematoxylin and eosin staining, use of special staining techniques especially differential stains such as Van Gieson, Masson's Trichrome greatly aid in better visualization of these changes. The principle of Masson's trichrome staining is dependent on the varying pore size among the various connective tissue components. The primary dye (acid fuchsin) which is of small size gets entrapped within the pores of the connective tissue components [5]. The decolourisation with the phosphotungstic and molybdic acid mixture aids in the washing away of the particles from the large pore sized components which is replaced by the aniline blue [5]. Thereby providing different colour contrast among various connective tissue components. A similar principle applies to Van Gieson staining technique [5]. Our extensive slide collection has enabled us to publish numerous articles in the past 3 years [6-13]. Based on these inspirations, we have planned to compare and evaluate muscle involvement and degeneration in advanced oral submucous fibrosis using three different stains namely, H\&E, Van Gieson, and Masson's Trichrome to employ them for better histological grading of the disease.

\section{MATERIAL AND METHODS}

\section{Study design and Sample}

The present study was a retrospective crosssectional study of advanced OSMF cases that were previously diagnosed using hematoxylin and eosin-stained sections from 2018 to 2019 
retrieved from department archives. 10 advanced OSMF cases were selected based on their H\&E stained sections which were evaluated based on the Khanna and Andrade classification system with connective tissue features such as hyalinization with fibrotic bands involving the muscle fibres and absence of cross striations or irregular striations in the muscle fibres representing muscle degeneration [5,14]. The slides were then stained using Van Gieson and Masson's trichrome.

\section{Van Gieson staining method}

Slides were deparaffinized using Xylene and rehydrated using alcohol. Later slides were placed in Hematoxylin for 8 minutes and rinsed in tap water. The slides were then dipped in acid alcohol and washed, followed by immersion in ammonia for bluing and washed. Later the slides were stained with Van Gieson for 3 minutes and rinsed in alcohol. The stain slides were air-dried and mounted. Deeper connective tissue with muscle was the control slide used to assess the quality of staining.

\section{Masson's Trichrome staining method}

The slides were deparaffinized with Xylene and rehydrated with alcohol. The slides were washed in distilled water. Sections were stained in Hematoxylin solution for 10 minutes and rinsed in tap water for 10 minutes. The slides were brought to distilled water then stained in Biebrich scarlet-acid fuchsin solution for 10-15 minutes. Sections were washed in distilled water. Later the sections were differentiated in phosphomolybdicphosphotungstic acid solution for 10-15 minutes or until the collagen is not red. Sections were transferred directly to aniline blue solution and stained for 5-10 minutes. The slides were rinsed briefly in distilled water and differentiated in 1\% acetic acid solution for 2-5 minutes. The slides were washed in distilled water, dehydrated very quickly through 95\% ethyl alcohol, and cleared in xylene.

\section{Evaluation of slides}

The slides were evaluated by two independent Oral Pathologists. The connective tissue parameters such as hyalinization, fibrosis and muscle degeneration were graded for each stain using criteria described by Reshma et al. [5] (Table I).

Table I - Description of the grading of each parameter in advanced OSMF

\begin{tabular}{|c|c|}
\hline GRADE & HYALINIZATION \\
\hline 1 & DESCRIPTION \\
\hline 2 & Absent \\
\hline 3 & Present \\
\hline & MXre pronounced \\
\hline 1 & Fibrosis involving superficial region of the muscle bundle \\
\hline 2 & Fibrosis involving deep region of the muscle bundle \\
\hline 3 & Muscle bundle replaced by fibrosis \\
\hline 4 & MUSCLEDEGENERATION \\
\hline 1 & Normal \\
\hline 2 & Superficial muscle degeneration \\
\hline 3 & Superficial and deep muscle degeneration \\
\hline
\end{tabular}

\section{Statistical analysis}

The scores were tabulated and Statistical analysis was performed using IBM SPSS 20 version software. Descriptive statistics was performed. Three parameters such as hyalinization, muscle involvement and muscle degeneration were compared among 3 different stains H\&E, Van Gieson and Masson's Trichrome. The variables were compared using Kruskal Wallis ANOVA. The Tukey HSD was done to assess the intergroup comparisons. $\mathrm{p}<0.05$ was considered to be statistically significant. 


\section{RESULTS}

The observation of the connective changes such as hyalinization, muscle fibrosis and muscle degeneration in advanced OSMF cases were graded and tabulated. Marked hyalinization was better appreciated in Masson's Trichrome (50\%) when compared to Van Gieson and H\&E (Figure 1). Fibrosis involving the skeletal muscle plane was better visualized in Masson's trichrome (10\% with muscle bundles replaced by fibrosis \& $90 \%$ showing extensive fibrosis) when compared to H\&E and Van Gieson (Figure 2) This was noted to be statistically significant $(\mathrm{p}=0.028)$. Masson's Trichrome demonstrated better visualization of degeneration of muscle fibres in deeper planes (60\% with deep degeneration and 30\% with superficial degeneration). This was statistically significant $(\mathrm{p}=0.016)$ (Figure 3$)$.

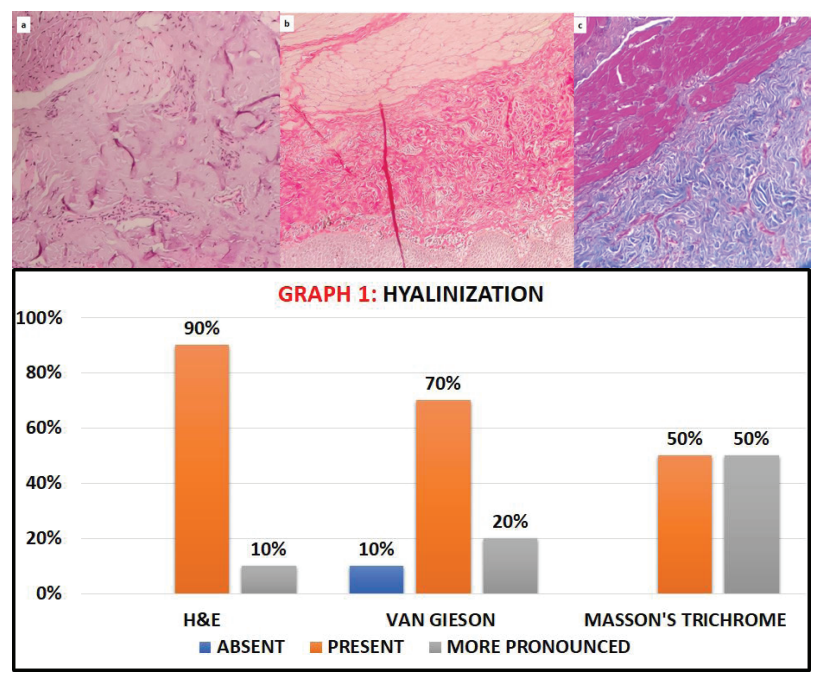

Figure 1 - (a) Photomicrograph showing homogenous glassy collagen in H\&E section, 10x magnification, (b) Photomicrograph showing red fibrillar homogenous collagen fibres and yellow muscle bundle, van Gieson (c) Photomicrograph showing better visualized fibrillar and homogenous collagen fibres stained in blue and muscle in pink by Masson's trichrome, 10x magnification (d) Bar graph depicting the association between the hyalinization and stains used. The X-Axis denotes the various stains used and $Y$-Axis denotes percentage in each grade. $50 \%$ of more pronounced hyalinization was visualized in Masson's Trichrome stain. Kruskal Wallis ANOVA was done ( $p=$ 0.121) which is not statistically significant.

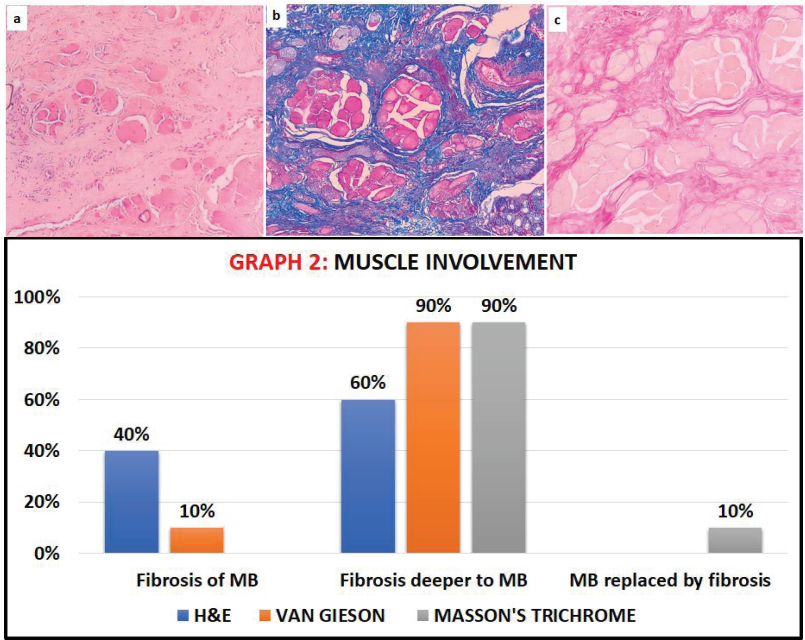

Figure 2-(a) Photomicrograph showing fibrosis extending into skeletal muscle in H\&E section, 10x magnification, (b) Photomicrograph showing better visualization of fibrosis in between the muscle bundle by Masson's trichrome, 10x magnification (c) Photomicrograph showing red fibrosis extending between the yellow muscle bundle, van Gieson 10x magnification (d) Bar graph depicting the association between the fibrosis with muscle involvement and stains used. The $\mathrm{X}$-Axis denotes the various grades in muscle involvement and Y-Axis denotes the percentage in each stain. 10\% showed muscle bundles replaced by fibrosis in Masson's Trichrome stain. Kruskal Wallis ANOVA was done $(p=0.028)$ which is statistically significant.

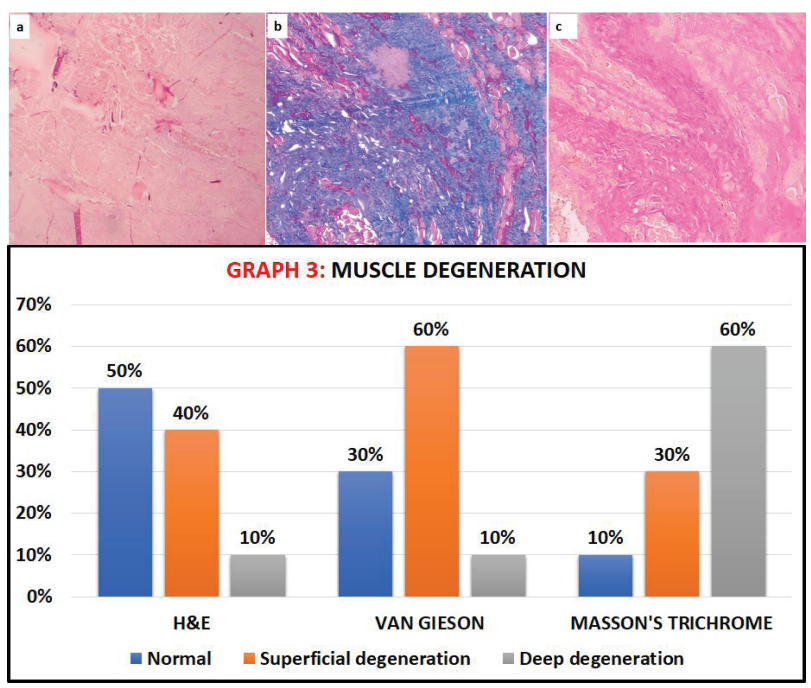

Figure 3 - (a) Photomicrograph showing fibrosis extending into skeletal muscle in H\&E section, 10x magnification, (b) Photomicrograph showing better visualization of fibrosis (blue) between the degenerated muscle bundles (Pink) by Masson's trichrome, 10x magnification (c) Photomicrograph showing red fibrosis extending between the yellow degenerated muscle bundle, van Gieson,10x magnification (d) Bar graph depicting the association between the muscle degeneration and stains used. The $\mathrm{X}$-Axis denotes the various stains used and Y-Axis denotes the percentage in each grade. $60 \%$ showed extensive muscle degeneration in Masson's Trichrome stain. Kruskal Wallis ANOVA was done $(p=0.016)$ which is statistically significant. 


\section{DISCUSSION}

OSMF is a potentially malignant disorder and chronic inflammatory condition which is characterized by subepithelial inflammatory reaction followed by hyalinization [15]. Based on the degree of subepithelial hyalinization and fibrosis, OSMF is classified either as very early, early, moderately advanced and advanced OSMF [16]. The classification of OSMF is characterized by the fibro-elastic changes associated with the underlying inflammatory reaction $[5,17,18]$. These changes are visible as eosinophilic bands (Edema and hyalinization) in routine H\&E sections $[5,17,18]$. The very early and early stages of OSMF have a greater number of fibroblasts and fewer collagen fibres $[5,17,18]$. As the disease progresses, the cellular content decreases and fibrous content increases. In advanced stages of the disease, there is evidence of extensive hyalinized smooth sheets of collagen fibres with extensive fibrosis and evidence of extensive degeneration of muscle fibres $[5,17,18]$. In routine H\&E staining, hyalinization and fibrosis appear as homogenous glassy eosinophilic bands extending or involving the adjacent skeletal muscle and muscle degeneration appears as loss of striations or irregular striations seen over the skeletal muscle $[17,18]$. Although H\&E can be used to grade OSMF, use of connective tissue special stains such as Van Gieson and Masson's Trichrome aid in better distinguishing these changes at the earlier stage which in turn helps in accurate grading and management of the advanced OSMF.

In the present study, 3 major connective tissue changes such as hyalinization, fibrosis involving the skeletal muscle and muscle degeneration were assessed among two different connective tissue stains such as Masson's Trichrome and Van Gieson which was then compared to the gold standard, H\&E staining. It was observed that $50 \%$ of the cases showed more pronounced hyalinization in Masson's trichrome, 20\% in Van Gieson and 10\% in H\&E respectively. This was noted to be in concordance with the previous literature. In the advanced stages of OSMF, the hyalinization of the collagen fibres extends deep into the submucosal tissues with decreased vascularity $[17,18]$. This is attributed to the chronic inflammatory process in the connective tissue that causes oedema in the collagen fibres $[17,18]$. Reshma et al stated that Van Gieson, Masson's Trichrome and Mallory's Trichrome provided better contrast between skeletal muscle and collagen fibres [5].

90\% showed fibrosis extending deep to the skeletal muscle bundles and $10 \%$ of cases showed muscle bundles replaced by fibrosis in Masson Trichrome staining whereas this replacement of muscle bundles by the fibres could not be appreciated in Van Gieson and H\&E. This was noted to be statistically significant $(p<0.05)$. Areas of degeneration of muscle bundles with the absence of striations and irregular striations were well-visualized using both Masson's trichrome when compared to Van-Gieson. $60 \%$ showed muscle degeneration in Masson's Trichrome staining and only 10\% were evident in H\&E and Van Gieson. This was noted to be statistically significant. Reshma et al concluded that superficial and deep fibrosis and muscle degeneration were better distinguished in Mallory's and Masson's Trichrome [5]. Thus it was in concordance with our study. Rooban et al. stated that fibrosis between muscle bundles increases as the disease progresses followed by degeneration of muscle fibres [19]. There is an excess of glycogen consumption which is to the cellular activity causing glycogen deficiency [19]. Thus the overactivity of muscles with diminished blood supply due to extensive fibrosis causes muscle degeneration in the advanced stages of the disease [19]. Ischemia leads to hypoxic injury to the cell, thus the cell undergoes an alteration in the shape attaining a round shape [20]. This causes an alteration in the pore size among the connective tissue cellular components [20]. 
This could be attributed to the difference in the uptake of Masson's trichrome and Van Gieson stains thus aiding a better contrast in visualizing the degeneration of muscle bundles Masson's Trichrome.

In this study, we have compared H\&E, VanGieson, Masson's Trichrome stain, to identify a better stain which would help us to distinguish the major connective tissue changes that aids in the accurate grading of OSMF which in turn aids in appropriate treatment planning and determining the prognosis of the patient. The identification of connective tissue changes aids to provide a personalized treatment plan for patients. Histopathologically on identifying extensive hyalinization, use of fibrinolytic agents such as hyaluronidase and placental extracts can be tried. In case of extensive fibrosis surgical excision can be carried out.

The sample size was small $(n=10$ for each stain) and only advanced cases of OSMF were included in our study. The comparison of the connective tissue changes in other grades of OSMF with the advanced OSMF was not done. The connective tissue changes assessed using these 3 different stains were not correlated with the clinical features. Thus in future, this study can be done on a large scale by comparing the connective tissue changes among varied grades of OSMF and by correlating them clinically.

\section{CONCLUSION}

OSMF is a debilitating disease of the oral mucosa that causes insidious scarring of oral cavity, pharynx and upper digestive tract. It is a crippling condition of the oral mucosa characterized by fibro-elastic changes in lamina propria, deeper connective tissue and degenerative changes in muscles with secondary changes in the epithelium. The grading and advancement of the disease are based on the extent of these changes (superficial or deeper connective tissue). Although H\&E stains the various components of connective tissue in shades of pink, there has been difficulty in distinguishing the connective tissue changes. Thus the use of adjuvant use of connective special stain such as Masson's Trichrome helps to better distinguish these changes in the connective than seen in routine H\&E stain. This could be appreciated in the present study with the use of Masson's trichrome stain thus exalting OSMF grading.

\section{Acknowledgments}

The authors are grateful to the department of oral pathology, Saveetha Dental college and hospitals for rendering help and support for the completion of the study

\section{Funding}

This research project was funded by none

\section{Conflict of interest}

The authors have no proprietary, financial, or other personal interest of any nature or kind in any product, service, and/or company that is presented in this article.

\section{Regulatory Statement}

This study was conducted in accordance with all the provisions of the local human subject's oversight committee guidelines and policies of: Saveetha Dental College and Hospitals. The approval code for this study is: IHEC/SDC/ OPATH-1802/21/32

\section{REFERENCES}

1. Biradar SB, Munde AD, Biradar BC, Shaik SS, Mishra S. Oral submucous fibrosis: a clinico-histopathological correlational study. J Cancer Res Ther. 2018;14(3):597-603.

2. Gajendra D, Arora S, Mujib A. A clinico-histopathological study of association between fibrosis and mouth opening in oral submucous fibrosis. J Oral Biosci. 2009;51(1):23-30.

3. Goel S, Ahmed J, Singh MP, Nahar P. Oral submucous fibrosis: a clinicohistopathological comparative study in population of Southern Rajasthan. J Carcinog Mutagen. 2010;1(2):108-11.

4. Rajendran R. Oral submucous fibrosis: etiology, pathogenesis, and future research. Bull World Health Organ. 1994;72(6):985-96. 
5. Reshma V,Varsha BK, Rakesh P, Radhika MB, Soumya M, D Mello S. Aggrandizing oral submucous fibrosis grading using an adjunct special stain: a pilot study. J Oral Maxillofac Pathol. 2016;20(1):36.

6. Jayaraj G, Sherlin HJ, Ramani P,K.rD, Santhanam A, Sukumaran G, et al. Malignant glomus tumour of the head and neck: a review. J Oral Maxillofac Surg Med Pathol. 2019;31(3):228-30.

7. Krishnan RP, Ramani P, Sherlin HJ, Sukumaran G, Ramasubramanian A, Jayaraj $G$, et al. Surgical specimen handover from operation theater to laboratory: a Survey. Ann Maxillofac Surg. 2018;8(2):234-8.

8. Sridharan G, Ramani P, Patankar S, Vijayaraghavan R. Evaluation of salivary metabolomics in oral leukoplakia and oral squamous cell carcinoma. J Oral Pathol Med. 2019;48(4):299-306.

9. Abitha T, Santhanam A. Correlation between bizygomatic and maxillary central incisor width for gender identification. Braz Dent Sci. 2019;22(4):45866.

10. Sujatha G, Muruganandan J, Priya VV, Shamsudeen SM. Knowledge and attitude among senior dental students on forensic dentistry: a survey. World JDent. 2018;9(3):187-91.

11. Padavala S, Sukumaran G. Molar incisor hypomineralization and its prevalence. Contemp Clin Dent. 2018;9(Suppl2):S246-50.

12. Alexander AJ, Ramani P, Sherlin HJ, Gheena S. Quantitative analysis of copper levels in areca nut plantation area: a role in increasing prevalence of oral submucous fibrosis: an study. Indian J Dent Res. 2019 Mar;30(2):261-6.
13. Sujatha G, Muruganandhan J, Vishnu Priya V, Srinivasan MR. Determination of reliability and practicality of saliva as a genetic source in forensic investigation by analyzing DNA yield and success rates: a systematic review. J Oral Maxillofac Surg Med Pathol. 2019;31(3):218-27.

14. Khanna JN, Andrade NN. Oral submucous fibrosis: a new concept in surgical management. Int J Oral Maxillofac Surg. 1995;24(6):433-9.

15. Kerr AR, Warnakulasuriya S, Mighell AJ, Dietrich T, Nasser M, Rimal J, etal. A systematic review of medical interventions for oral submucous fibrosis and future research opportunities. Oral Dis. 2011;17 Suppl 1:42-57.

16. Venkatakrishnan S, Ramalingam V, Palanivel S. Classification of oral submucous fibrosis using SVM. Int J Comput Appl. 2013;78(3):8-11.

17. Ali FM, Patil A, Patil K, Prasant MC. Oral submucous fibrosis and its dermatological relation. Indian Dermatol Online J. 2014;5(3):260-5.

18. Abdul SN. Oral submucous fibrosis and its relation with stromal vascularity: a systematic review. EJMHS. 2020;2(2):1-3.

19. Rooban T, Saraswathi TR, AI Zainab FH, Devi U, Eligabeth J, Ranganathan K. A light microscopic study of fibrosis involving muscle in oral submucous fibrosis. Indian J Dent Res. 2005;16(4):131-4.

20. Miller MA, Zachary JF. Mechanisms and morphology of cellular injury, adaptation, and death. In: Zachary JF. Pathologic basis of veterinary disease. 6th ed. Maryland Heights: Mosby;2017. p. 2-43.

\section{Dr. Krishnapriya Umashankar}

(Corresponding address)

Post Graduate, Master of Dental Surgery, Oral Pathology

Department of Oral Pathology, Saveetha dental college and hospital, Saveetha Institute of

Medical and Technical Sciences, Chennai-600077, Tamil Nadu, India.ORCID: 0000-0002-

1900-9393

Email: Krishnapriya91@gmail.com

Date submitted: 2020 Jul 09

Accept submission: 2020 0ct 31 